production and restrictions on the export of this crop. This increased the market price of wheat, which probably helped to spark the Arab Spring 5 . So the reallocation of crop production - and the associated nitrogen use - through international trade can affect food and national security. It could even affect energy security if the increasing use of crops to produce biofuels continues.

In theory, international trade policy could discourage fertilizer subsidies in countries that overuse them and encourage such subsidies where farmers currently cannot afford fertilizer. It might also be possible for international policies to concentrate crop production in exporting countries that use nutrients efficiently, but the complex consequences of this would be difficult to predict using available knowledge. In all cases, it will be crucial to evaluate how international trade affects the efficiency, efficacy and resilience of agricultural production.

Coordinating nitrogen use on sub-national or finer scales seems practical, but the rate at which nitrogen is applied to croplands is usually determined to maximize profit, rather than nitrogen-use efficiency ${ }^{6}$. Financial incentives and regulatory policies ${ }^{7}$, as well as outreach efforts by governments and scientists, can persuade or require farmers to consider how their management decisions affect downstream and downwind ecosystems through nitrogen pollution, and thus to optimize nitrogen management for both profit and efficient nitrogen use ${ }^{8}$.

A benefit of Mueller and colleagues' proposal

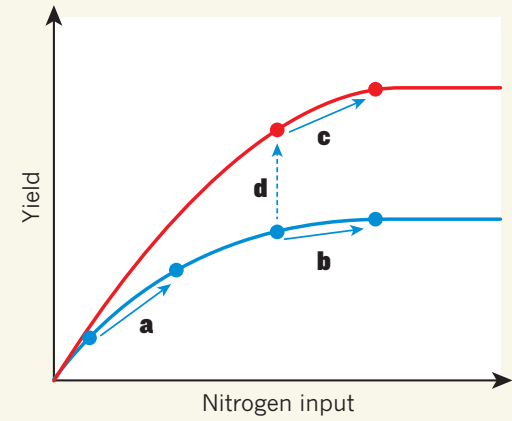

Figure 2 | The effects of nitrogen-containing fertilizers on crop yields in different regions. The left-hand side of the blue curve represents regions, such as sub-Saharan Africa, where yield increases are limited by nitrogen availability. The right-hand side represents regions, such as China, where cropland is saturated with nitrogen. A fixed increase of nitrogen produces a much bigger increase in crop yield on the left-hand side of the curve (a) than on the right-hand side (b).

The red curve depicts regions, such as the United States, where climate and soil conditions, and/or the use of advanced technologies and management practices, generate greater yield improvements from increased nitrogen use (compare c with b). Mueller et al. ${ }^{3}$ report that the reallocation of nitrogen resources to regions that benefit most from the nutrient's addition could greatly improve global nitrogen-use efficiency. Further improvements could be achieved by shifting regions from the lower to the upper curve (d) - for example, through the adoption of new technologies and management practices. for the efficient reallocation of nitrogen is that it would not require any additional development, or adoption of farming technologies and management practices. The opportunity they present therefore seems too good to miss. But to truly optimize environmental and socio-economic benefits, nitrogen reallocation would need to be accompanied by the allocation of other resources, such as phosphorus and water, and by the adoption and development of new technology ${ }^{9}$ (Fig. 2d). A holistic approach that considers how all of these changes would affect the environment, the economy, society and the resilience of the food-supply system is therefore needed to develop nitrogen reallocation as a strategy for sustainable agricultural production.

Xin Zhang is at the University of Maryland Center for Environmental Science, Frostburg, Maryland 21532, USA.

e-mail:xin.zhang@umces.edu

1. Tilman, D., Balzer, C., Hill, J. \& Befort, B. L. Proc. Natl Acad. Sci. USA 108, 20260-20264 (2011).

2. Zhang, X. et al. Nature 528, 51-59 (2015).

3. Mueller, N. D. et al. Glob. Biogeochem. Cycles http:// dx.doi.org/10.1002/2016GB005515 (2017).

4. Lambin, E. F. \& Meyfroidt, P. Proc. Natl Acad. Sci. USA 108, 3465-3472 (2011).

5. d'Amour, C. B., Wenz, L., Kalkuhl, M., Steckel, J. C. \& Creutzig, F. Environ. Res. Lett. 11, 035007 (2016).

6. Zhang, X., Mauzerall, D. L., Davidson, E. A., Kanter, D. R \& Cai, R. J. Environ. Qual. 44, 312-324 (2015).

7. Van Grinsven, H. J. et al. J. Environ. Qual. 44, 356-367 (2015).

8. Davidson, E. A., Suddick, E. C., Rice, C. W. \& Prokopy, L. S. J. Environ. Qual. 44, 305-311 (2015).

9. Bouwman, A. F. et al. Sci. Rep. 7, 40366 (2017)

\title{
Coral crisis captured
}

Ocean warming has triggered three major bleaching episodes on the Great Barrier Reef over the past two decades. On page 373, Hughes et al. present an analysis of the extent and severity of these events (T. P. Hughes et al. Nature 543, 373-377; 2017).

Corals become bleached when stresses such as high temperature kill the symbiotic algae that lend corals their striking colours (pictured: Great Barrier Reef coral with algae intact) and supply them with energy in the form of sugars. Prolonged bleaching can result in coral mortality.

In 2016, a massive wave of bleaching struck the reef after an El Niño event brought abnormally warm waters to the region. Hughes et al. mapped this bleaching across the entire length of the reef through the use of aerial surveys and underwater measurements.
The authors found that the 2016 event was much greater in scope and severity than previous bleaching events in 1998 and 2002. In 1998, 45\% of individual reefs surveyed escaped bleaching. This figure dropped to $42 \%$ in 2002 and to just $9 \%$ in 2016. Compared with the two earlier episodes, extreme bleaching events in which more than $60 \%$ of corals in a given area lost their colour - were more than four times as frequent in 2016.

Hughes et al. show that the observed distribution of bleaching can be explained by the spatial patterns of ocean warming. Local management of fishing pressure and water quality provided little protection, suggesting that a curb in global warming will be needed to secure a viable future for the world's most spectacular reef system. Anna Armstrong

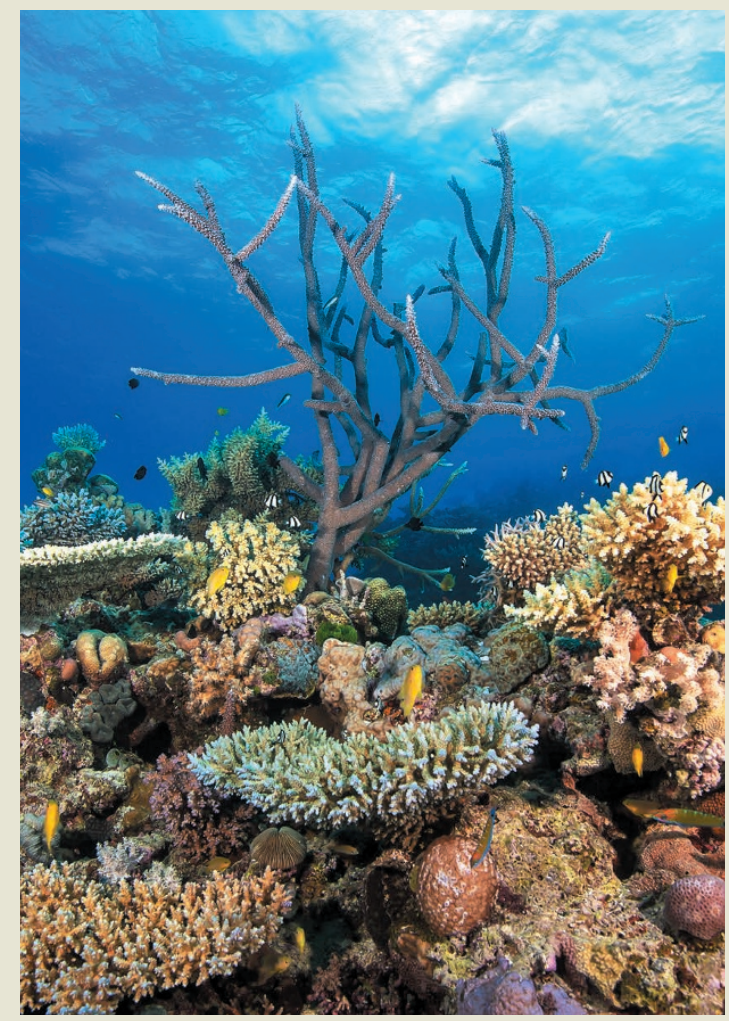

